\title{
Current Strategies for Cancer Gene Therapy
}

\author{
Yufang Zuo, Xiaofang Ying, Hui Wang, Wen Ye, \\ Xiangqi Meng, Hongyan Yu, Yi Zhou, \\ Wuguo Deng and Wenlin Huang \\ State Key Laboratory of Oncology in South China, Cancer Center, \\ Sun Yat-sen University, Guangzhou, \\ PR China
}

\section{Introduction}

Cancer is one of the most lethal diseases in the world. Traditional methods for cancer treatment are surgery, chemotherapy and radiotherapy. Early stage cancer patients may be cured by radical surgery and (or) chem(radio-)therapy. However, advanced cancer patients usually suffer from chem(radio-)resistance or metastasis, most of which can not be controlled by current therapy. Furthermore, traditional chem(radio-)therapy will bring patients with severe side effects as they not only kill cancer cells, but also normal cells.

Many investigators believe the potential to make great progress in cancer treatment lies in understanding the molecular biology of cancer and exploiting effective agents targeting abnormal molecules which regulate the growth and metastasis of tumor $\mathrm{Ku}$ and Ilson, 2010). This is called targeting therapy, which can selectively kill cancer cells with minor side effects. Effective targeting therapy lies on good targets chosen and the methods used to deliver targets into the tumor mass safely and efficiently. During the past decades, various important tumor targets were exploited.

\section{Targeting tumors by dysfunctional pathways}

Overexpression of receptors and the abnormal activation of intracellular kinase mutations, resulting downstream of signaling pathways enhanced, leading to cell transformation, proliferation, resistance to apoptosis and eventually promote tumorigenesis. Therefore, signaling pathway has become a potential therapeutic target for cancer.

\subsection{Targeting the EGFR signaling pathway}

EGFR pathway mediates many important physiological processes in both normal and cancerous cells. Because of the function of the EGFR pathway, a number of therapeutic agents have been developed aiming to target EGFR. To date, five EGFR-targeted agents have been approved by the FDA for treating cancer patients. Erlotinib (OSI-774, Tarceva) was approved to treat metastatic non-small cell lung cancer (NSCLC) as single agent and to be used in combination with gemcitabine for pancreatic cancer. Another small molecule EGFR kinase inhibitor, Gefitinib (ZD1839, Iressa), is being used for locally advanced and metastatic NSCLC (Lo). Lapatinib (GW572016, Tykerb/Tyverb) is an EGFR/HER2-dual 
targeting small molecule inhibitor, it used in combination with other drugs, for patients with advanced or metastatic breast cancer whose cancer is HER2 positive and has failed to respond to other drugs (Moy et al., 2007).

\subsection{Targeting the NF-kB pathway}

Many cancer cells show aberrant or constitutive NF-kB activation which mediates resistance to chemo- and radio-therapy. Based on the pivotal role of the NF-KB pathway in the tumor progression, the NF- $\mathrm{KB}$ signaling pathway has become a potential target for pharmacological intervention. Strategies for blocking NF-кB include a NF-кB targeting strategy and an upstream strategy. The NF- $\mathrm{kB}$ targeting strategy involves blocking the activation of NF-KB signaling pathway, includes: (a) glucocorticoids used to block the transactivation of NF-kB (D'Acquisto et al., 1998). (b) decoy oligodeoxynucleotides (ODNs) used to block the DNA binding of NF-KB (Karin et al., 2004). On the other hand, the upstream strategy includes: (a) IKK inhibitors NSAIDs, sulfasalazine, arsenic trioxide, curcumin, thalidomide; (b) proteasome inhibitors PS-341, MG132; (c) the recombinant adenovirus-mediated overexpression of the IKBa gene. (d) cell-permeable peptides SN-50; (e) antioxidants disulfiram, glutathione (Chen et al., 2002; Tomita et al., 2003).

\subsection{Targeting the PTEN/PI3K/AKT signaling pathway}

PTEN/PI3K/AKT constitutes an important pathway regulating the signaling of cell proliferation, survival, apoptosis, and metabolism. Many components of this pathway have been described as causal forces in cancer. Once the activity of mTOR induced by disfunction of PTEN/PI3K/AKT pathway, the promotion of tumor proliferation and growth are achieved through its downstream targets. A number of basic research studies and clinical trials have investigated that rapamycin, the potential of the selective mTOR inhibitor could inhibit activity of both mTOR and AKT, suggesting that it may be an effective therapeutic blockade of PI3K signaling (Guertin and Sabatini, 2007). PI3K inhibitors, TGX115, LY294002 derivatives have shown to have greater solubility, lower toxicity, improved pharmacodynamics, and more specific PI3K selectivity than LY294002 (Granville et al., 2006). In addition, PX-866a, wortmannin derivative has more potent and less toxic effects than wortmannin (Jiang and Liu, 2008). SF1126 is a small molecule inhibitor that can inhibit all isoforms of PI3K class. In preclinical studies, it has been identified to be effective for tumor treatment in a variety of mouse tumor models, including prostate, breast, lung, multiple myeloma, and other cancers (Hennessy et al., 2005). Lipid-based inhibitors of Akt were the first group of inhibitors to be developed. Perifosine is the best-characterized Akt inhibitor, which inhibits the translocation of Akt to the cell membrane. It can inhibit the cell growth in different solid tumors (Martelli et al., 2003). Several other Akt inhibitors such as the indazole-pyri-dine A-443654 and 9-methoxy-2-methylellipticinium acetate (API-59-OMe) have been identified. A-443654 was shown to increase the effect of paclitaxel treatment both in vitro and in vivo (Han et al., 2007). API-59-OMe can inhibit cell growth and induce apoptosis of several different human cancer cells, including prostate, breast, endometrial and ovarian cancers (Jin et al., 2004; Tang et al., 2006).

\subsection{Targeting the MAPK signaling pathway}

The RAS-mitogen activated protein kinase (MAPK) signaling pathway not only promotes cell proliferation, but also mediates cell survival. The activity of this pathway was reported to be upregulated in a broad spectrum of human tumors. In this signalling pathway, RAS, 
RAF and MEK proteins have unique features that make it a good therapeutic target. By inhibiting the post-translational addition of farnesyl group to RAS by farnesyltransferase, it was thought that Farnesyltransferase inhibitors (FTIs)would be able to target human tumors in which RAS was constitutively activated (Sebolt-Leopold and Herrera, 2004). Several FTIs such as BMS-214662, Sarasar and Zarnestra have been studied in patients diagnosed with a range of cancers. FTIs could be specific and effective therapeutic agents, however, clinical data obtained so far leads us to conclude that these agents do not represent a viable approach to blocking signal transduction through the RAS-MAPK pathway. Therefore, several small molecule RAF inhibitors have now been reported. According to published reports, only BAY 43-9006 has reached the clinical testing stage. It has completed Phase I and Phase II trials. It has been reported that this agent is generally well tolerated. However, the toxicities involving the gastrointestinal track and the skin have existed. Phase III trials to be focusing on patients with renal-cell carcinoma indicated that BAY 43-9006 lack of specificity. So, although BAY 43-9006 has promise as an anticancer agent, it is difficult to assess the impact of RAF inhibition on observed clinical outcomes. The first MEK inhibitor reported to inhibit tumor growth in vivo was CI-1040 (Sebolt-Leopold et al., 1999). There was evidence of antitumor activity in the Phase I trial, however, similar results were not observed in Phase II trials, so PD0325901, which is structurally highly similar to CI-1040, was subsequently developed. The anticancer activity of PD0325901 was improved compared with CI-1040. The longer duration and greater solubility leading to improved bioavailability, and increased metabolic stability. Therefore, PD0325901 viewed as a significantly more potent MEK inhibitor (Sebolt-Leopold and Herrera, 2004).

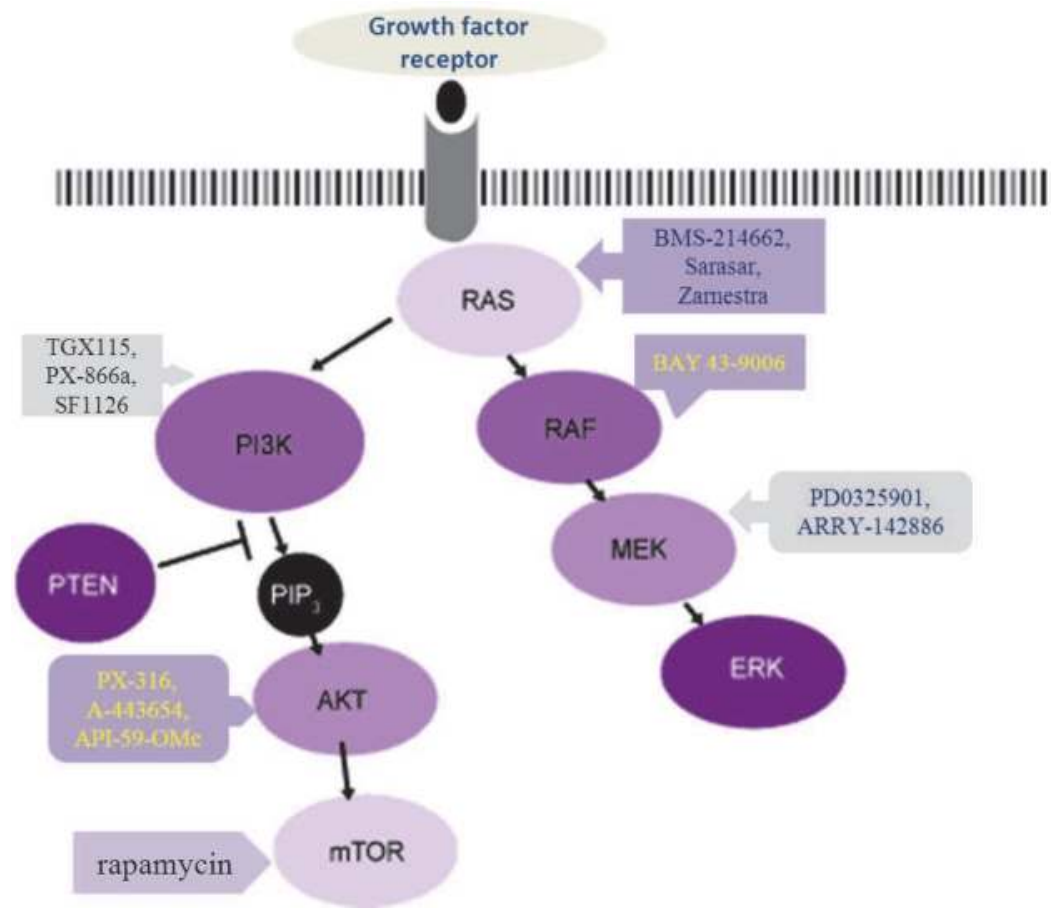

Fig. 1. Targeting the PTEN/PI3K/AKT and MAPK signaling pathway 


\section{Targeting tumors with tumor suppress gene p53}

Clinical studies have shown that p53 is a tumor suppressor which mutates in about $50 \%$ of human cancers, and where the gene itself is not mutated, its signal pathway functionally inactivated. Three decades of researches in p53 have reached an understanding of p53 playing a key role in the regulations of many different genes in response to a wide variety of epigenetic stresses.

\subsection{Regulation of p53 expression}

In normal cells, p53 restrains its expression and function to maintain normal homeostasis. Critical for the control of p53 function are its two main negative regulators: Mdm2 and Mdmx. Duplicated from a single ancestral gene, Mdm2 and Mdmx have similar sequences. They bind to p53 via an N-terminal hydrophobic pocket, thus inhibiting transactivation function of p53 (Kruse and Gu, 2009). The C-terminal of both Mdm2 and Mdmx contain a RING domain which has intrinsic E3 ubiquitin ligase activity and it targets p53 for ubiquitin-dependent degradation by proteasome both in nucleus and cytoplasm (Deshaies and Joazeiro, 2009). Mdm2 and Mdmx also induce the exportation of p53 from the nucleus to the cytoplasm. Thus, these two proteins negatively regulate p53 by both suppression of transactivation and post-translational destabilization.

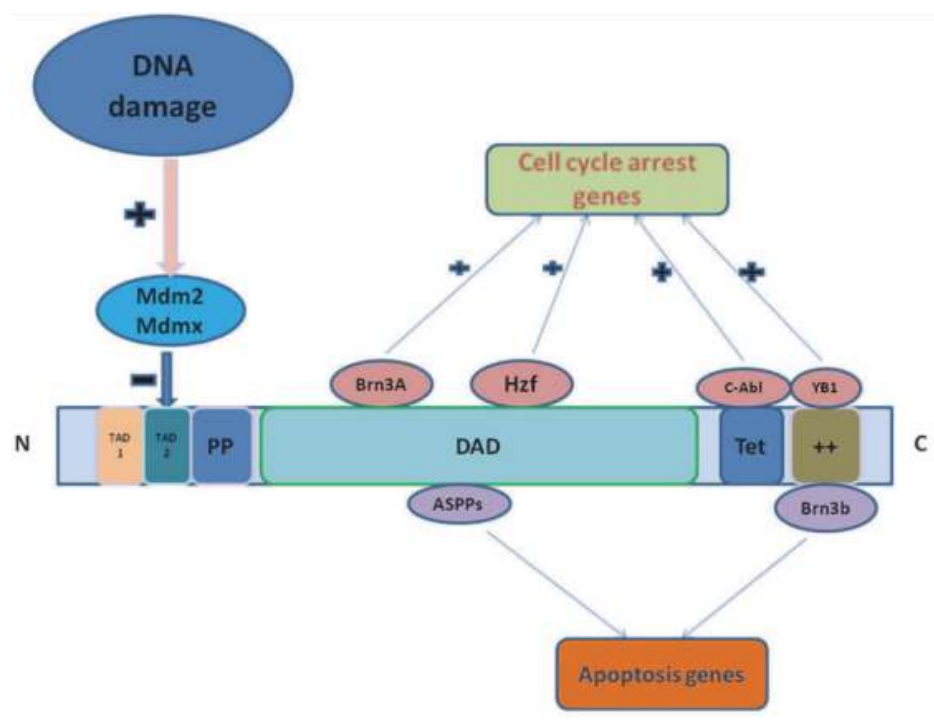

Fig. 2. Targeting tumors with tumor suppress gene p53

\subsection{Conformation of p53}

The p53 protein contains three main functional domains: N-terminal harbors transcriptional activation domain 1 (TAD1, residues 20-40), TAD2 (residues 40-60) which interacts with $\mathrm{Mdm} 2$ and Mdmx, and the proline domain (PP, residues 60-90); in the middle lies the central core sequence-specific DNA-binding domain (DAD, residues 100-300), it interacts with its target genes or proteins; and C-terminal contains the tetramerization domain (Tet, 
residues 325-356) and lysine-rich basic C-terminal domain (++, residues 363-393) which regulates DNA-binding. Interacts mainly with sequence-specific DNA binding sites of its target agents, p53 starts series of cellular responses: cell-cycle arrest, apoptosis, DNA-repair and so on. For example, Brn3A and Hzf with DAD, C-Abl with Tet, YB1 and p18/Hamlet with ++ selectively induce p53 activation of cell-cycle arrest genes like p21. Conversely, ASPPs with DAD and Brn3b, and so on with the p53 C-terminal selectively induce apoptotic genes like PUMA and Bax (Vousden and Prives, 2009).

\subsection{Function of p53}

Here comes to questions: When do cells perform cell-cycle arrest, and when do they bring about senescence and apoptosis? Some researches hypothesis that the outcome of p53 activation mostly depends on the type of tissue and stress, how severe the stress is, the microenvironment, and the post-transcriptional modification. With mild impact to DNA, p53 may stabilize the genes, including DNA repair and activating anti-oxidant genes. As a result, p53 acts as a protector by preventing the generation of oncogenic lesions. Conversely, once severe stress happens, like oncogene activation, lethal DNA damage or hypoxia, p53 may start senescence and apoptosis, eliminating badly injured cells which cannot be rescued by cell-cycle arrest (Vousden and Lu, 2002).

\subsection{Wild-type p53 in cancers}

In tumors which have wild-type p53 reduced, disturbing the interaction between p53 and $\mathrm{Mdm} 2 / \mathrm{Mdmx}$ may rationally restore $\mathrm{p} 53$ function and may enhance sensitivity of tumors to chemotherapy and radiotherapy.

Nutlins, a well studied inhibitor family of the Mdm2-p53 complex, are highly selective for $\mathrm{Mdm} 2$ and they can tightly bind to their receptors (Dickens et al.). In the Nutlin family there is Nutlin-3, it competes for binding to Mdm2, so displaces p53 protein and releases it to function normally in cancer cells derived from hematologic malignancies (Secchiero et al., 2008). The molecular pathways in the Nutlin-3 induced responses still wait to be explored.

A small molecular compound, RITA, induces wild-type p53 activation and accumulation thus programs apoptosis in different tumor cell lines of colon, lung, breast, etc both in vitro and in vivo. It prevents interaction between p53 and Mdm2 through binding to the 1-63 residues of the p53 protein $\mathrm{N}$-terminal (Issaeva et al., 2004).

\subsection{Mutant p53 in cancers}

A large-scale sequencing of various tumor cells proved that p53 mutations, mostly DNA binding domain mutations are common events.

Small molecular compounds for mutant p53 reactivation via different mechanisms have been identified in recent years. CP-31398, stabilizes the conformation of DNA binding domain to restore the function of several p53 mutants. Foster. et al reported that CP-31398 suppressed the growth of both human tumor cells in vitro and xenograft tumors in mice (Foster et al., 1999).

Similar with CP-31398, PRIMA-1 also serves to suppress tumor cell growth by reactivating the transcriptional function of mutant p53 and inducing cofactors responsible in p53mediated apoptosis like PUMA, Noxa, and Bax, which induce caspase activation, especially caspase-2 (Bykov et al., 2002). Rescue tumor suppression function of p53 will pave the way for future anti-cancer therapy. 
For the purpose of inducing p53 activities in a desirable way, a wide range of unknown fields from the p53 posttranscriptional modifications, cofactors to network of targeted agents wait to be fetched.

\section{Targeting tumors by anti-angiogenesis}

Cytotoxic approaches to killing tumor cells, based on their increased rate of proliferation relative to normal cells, have been the mainstay of cancer therapy for decades. However, over 30 years ago, as proposed by Folkman in 1971, angiogenesis is required for tumor, so targeting angiogenesis is a significant approach in inhibiting solid tumor growth and hence, limit cancer progression (Folkman, 1971).

Angiogenesis is the formation of new blood vessels from pre-existing ones. The understanding of the angiogenic mechanisms and the successful use of several angiogenesis inhibitors in animal models, have led to clinical applications of anti-angiogenic therapy. This strategy has several advantages over traditional chemotherapy, in principle, including side effects and less toxicity, a reduced risk for development of resistance, and a general broad spectrum of activity. More important, anti-angiogenic approaches can efficiently target both low and high proliferating tumor cells, so unlike conventional cytotoxic chemotherapies that are more effective against fast growing tumors, anti-angiogenic therapy could act against a broader range of cancers. The expected results are different from traditional cancer therapies, the first aim of anti angiogenesis is to stabilize the disease rather than to eradicate the tumor mass, unlike radiotherapy or chemotherapy; however these strategy can be used in concert (Bisacchi et al., 2003).

\subsection{Potential anti-angiogenic factors for gene therapy}

Induction of the angiogenic switch depends on a local change in the balance between inhibitors and activators of angiogenesis. The switch to an angiogenic phenotype of tumor requires downregulation of angiogenesis inhibitors and upregulation of angiogenic factors (Dell'Eva et al., 2002). Until now, many angiogenic peptides have been identified, including vascular endothelial growth factor (VEGF) and vascular permeability factor (VPF), basic and acidic fibroblast growth factor (FGF), epidermal growth factor (EGF), platelet-derived epidermal cell growth factor (PD-ECGF), platelet-derived growth factor (PDGF), insulin-like growth factors (IGFs), interleukin-8 (IL-8), transforming growth factor- $\alpha$ and $\beta$ (TGF- $\alpha$ and $\beta)$, heparin growth factor, granulocyte colony stimulating factor, E-selectin, angiogenin, tumor necrosis factor- $\alpha$ (TNF- $\alpha)$. Angiogenic factors released by tumor cells stimulate endothelial cells (EC) which become activated, providing growth factors (FGF-1,-2) and matrix metalloproteinases (MMPs). Proteolytic activities of the MMPs degrade the surrounding tissue and vascular membrane, leading to EC proliferation, migration and new capillary formation.

Thus, the goal of anti-angiogenic gene therapy is to switch the local balance between angiogenic factors and angiogenic inhibitors in tumor microenvironment to the antiangiogenic phenotype, targeting one or more events of angiogenesis cascade. The more attractive angiosuppressive factors for clinical trials are: naturally occurring inhibitors of angiogenesis, agents that interfere with vascular basement membrane and extracellular matrix MMP inhibitors, angiostatic steroids and others, anti-adhesion molecules antibodies 
and miscellaneous drugs that modulate angiogenesis by diverse mechanisms of action (O'Reilly et al., 1997).

\subsection{Clinical trials targeting tumor angiogenesis}

The greatest clinical success with the antiangiogenic strategy to date, has been achieved with bevacizumab, the antibody to VEGF. Bevacizumab blocks the binding of VEGF-A to its receptors, VEGFR-1 and VEGFR-2. In rectal cancer patients, this VEGF signaling inhibitor reduced tumor microvessel density, blood flow and interstitial pressure, and increased the percentage of vessels covered by pericytes (Willett et al., 2004).

Endostatin is a $20-\mathrm{kDa}$ proteolytic $\mathrm{COOH}$-terminal fragment derived from collagen XVIII58. Endostatin reduces endothelial cell proliferation and migration, significantly reduces invasion of endothelial as well as tumor cells into the reconstituted basement membrane and acts as a potent inhibitor of angiogenesis and tumor growth. In preclinical studies, expression of endostatin decreased tumor vascularization 3-fold with a concomitant 3-fold increase in the number of apoptotic cells. Endostatin is the first endogenous angiogenesis inhibitor to enter clinical trials. The earliest phase I trials were published in 2002 and 2003 at The University of Texas M.D. Anderson Cancer Center. The final results show that the anti-angiogenic drug was safe and reduced blood flow in patients. There was some shrinkage of tumors among the participants, and two patients showed encouraging results (Thomas et al., 2003). A Chinese phase III trial using recombinant endostatin in combination with chemotherapy in NSCLC has exhibited a significant increase in response rates and time to progression. Another potent angiogenesis inhibitor is angiostatin $(38 \mathrm{kDa})$, which is generated as a result of proteolytic cleavage of plasminogen and comprises the first four triple loop disulphide-linked structures of plasminogen, termed kringle domains (O'Reilly et al., 1994). Currently, phase II/III clinical trials of endostatin and angiostatin are ongoing, and preliminary data analysis show minimal toxicities but anti-tumor results are inconsistent.

Now, more than 300 anti-angiogenic molecules targeting different signalling pathways and over 20 angiogenic growth factors are being tested for their potential anti-cancer efficacies at preclinical and clinical stages. Eight new drugs in which anti-angiogenic activity is considered to be central to their therapeutic effects have been approved by the FDA in the United States for the treatment of cancer (Table 1) (Park and Dilda).

\subsection{Perspectives}

Antiangiogenic methods have changed the landscape in traditional cancer therapy after the initial clinical success of bevacizumab in 2004. Future development of antiangiogenic drugs targeting various pathways with different principles, particularly in combination therapy settings, is expected to significantly improve therapeutic efficacies. One of the important approaches of increasing therapeutic efficacy is to optimize the drug delivery systems that enable accurate drug release only in malignant tissues, persistent release and tightly controlled release of antiangiogenic agents. Long-term delivery is particularly advantageous for clinical benefits as withdrawal of these drugs might cause a rebound angiogenic activity in tumors. However, persistent release of the same drug in cancer patients might elicit evasive refractoriness to antiangiogenic therapy. This dilemma may be resolved using a smart microchip delivery system that simultaneously or sequentially releases multiple drugs targeting different pathways. 


\begin{tabular}{|c|c|c|}
\hline Angiogenic inhibitor & Target & FDA approved for \\
\hline $\begin{array}{l}\text { Avastin/bevacizumab } \\
\text { (Genentech) }\end{array}$ & VEGF & $\begin{array}{l}\text { Non-small cell lung carcinoma, } \\
\text { metastatic colorectal cancer and } \\
\text { breastcancer }\end{array}$ \\
\hline $\begin{array}{l}\text { Cetuximab/Erbitux (Bristol- } \\
\text { Myers Squibb ImClone) }\end{array}$ & EGFR & $\begin{array}{l}\text { Metastatic colorectal carcinoma and } \\
\text { head and neck cancer }\end{array}$ \\
\hline $\begin{array}{l}\text { Panitumumab/Vectibix } \\
\text { (Amgen) }\end{array}$ & EGFR & Metastatic colorectal carcinoma \\
\hline $\begin{array}{l}\text { Erlotinib/Tarceva (Genentech } \\
\text { OSI Roche) }\end{array}$ & EGFR & $\begin{array}{l}\text { Non-small cell lung carcinoma and } \\
\text { pancreatic cancer }\end{array}$ \\
\hline Sunitinib/Sutent (Pfizer) & $\begin{array}{l}\text { Multi- } \\
\text { kinase } \\
\text { inhibitor }\end{array}$ & $\begin{array}{l}\text { Advanced renal cell carcinoma and } \\
\text { gastrointestinal tumours }\end{array}$ \\
\hline $\begin{array}{l}\text { Sorafenib/Nexavar (Bayer } \\
\text { Onyx) }\end{array}$ & $\begin{array}{l}\text { Multi- } \\
\text { kinase } \\
\text { inhibitor }\end{array}$ & $\begin{array}{l}\text { Advanced renal cell carcinoma and } \\
\text { advanced hepatocellular carcinoma }\end{array}$ \\
\hline
\end{tabular}

Table 1. Anti-angiogenic therapeutics FDA approved for the treatment of cancer.

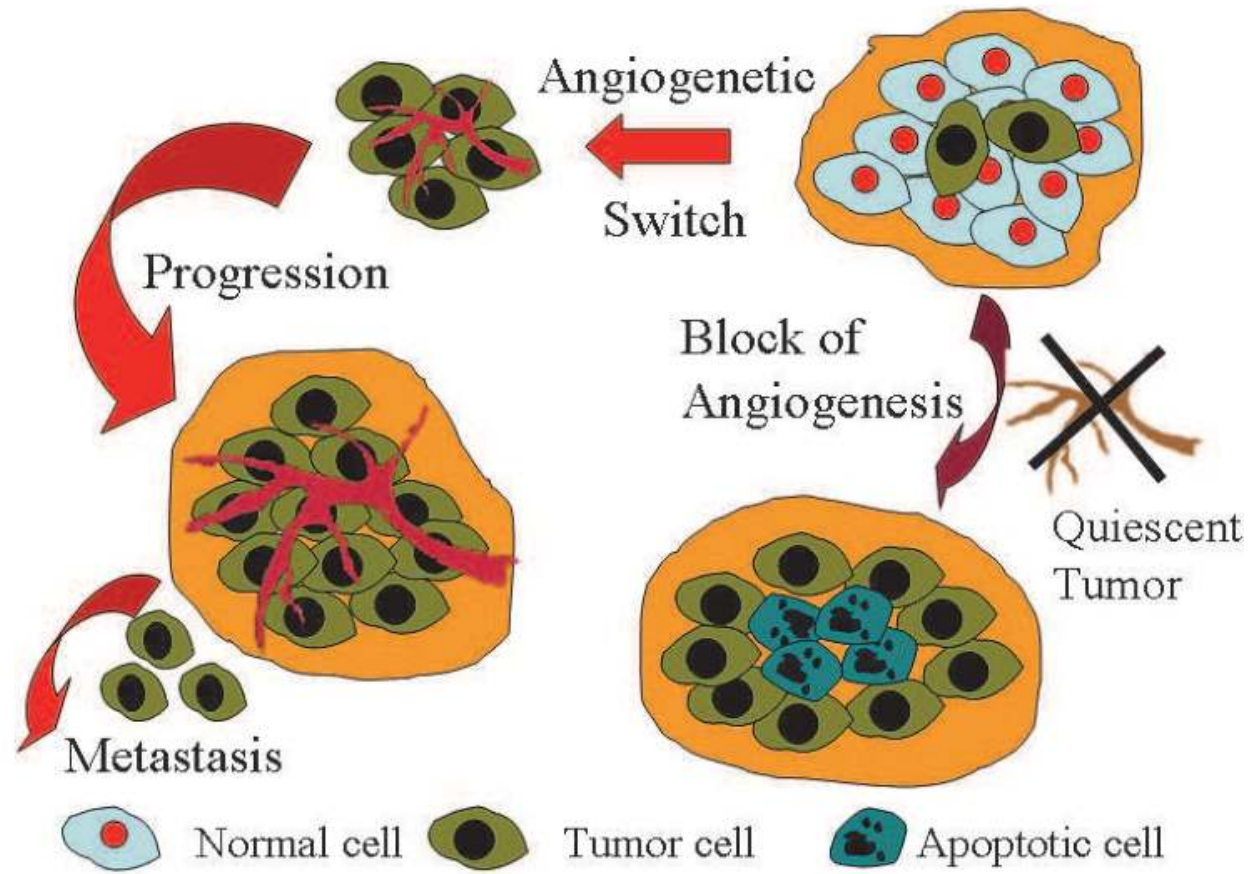

Fig. 3. Targeting tumor by antiangiogenesis 


\section{Targeting tumors with monocloning antibody}

For several decades, antibodies has been hoped to become a 'magic bullets' to cure patients, and this vision came true with the development of hybridoma technology by Kohler and Milstein (Kohler and Milstein, 1975). The antibodies are Y-shaped proteins with two identical light chains and two identical heavy chains. The arms of the $Y$ identify antigens, and the stem of $\mathrm{Y}$ alerts and recruits the components to attack the molecular targets once bounded.

Present, more than 400 mAbs entered commercial clinical development and anticancer mAbs comprised almost half of the total mAbs (Reichert et al., 2005). To date, a dozen of anticancer mAbs have been approved for marketing by FDA. There are two modes that $\mathrm{mAbs}$ destroy the target tumor cells, one is direct way by conjugating radioactive toxins or triggering apoptosis. Another is the indirect way through activating immune system components or blockade of critical receptors.

The conjugated mAbs can increase the specificity of chemo- or radiation therapy. Drugs composed of the conjugate can be produced by chemical linkers, while the proteins can be produced by either chemosynthesis or genetic engineering. However, some challenges exist in the development of immunotoxins since the protein toxins can lead to immunogenic action in human and the drug toxins which may lack potency for the little doses degrade in the way to the tumor site. Another limitation is that immunotoxins require internalization to gain a cytotoxic effect on tumor cells.

In the recent data, over half of the mAbs are unmodified mAbs. The characteristics like average half-life, vary with the isotype of the unmodified mAbs are determined to be the crystallizablefragment $(\mathrm{Fc})$ region. A common mode of mAbs function is to activate the components of the human immune system attacking the target cancer cells. Once binding to target, mAbs can call up effector cells to activate the complement. These actions are known as antibody-dependent cell cytotoxicity (ADCC) and complement-dependent cytotoxicity $(\mathrm{CDC})$, and they are mediated by the Fc portion of mAbs.

\subsection{Targets in solid tumors}

EGFR family includes EGFR(c-erbB-1), HER2/ neu (c-erbB-2), HER3(c-erbB-3), and HER4 (cerbB-4). EGFR overexpressed in many solid tumors, such as non-small cell lung cancer, colorectal cancer, breast cancer, head and neck cancer, and prostate cancer. Some anti-EGFR $\mathrm{mAbs}$ can inhibit tumor cell growth and activate tyrosine kinases. Cetuximab, a chimeric form of anti-EGFR antibody can objective anti-tumor responses alone, or in combination with other treatment strategies for the overexpressing EGFR cancers. A second EGFRtargeted mAbs, Panitumumab, was produced in a muse while the genes of antibody came from human (Mendez et al., 1997).

bold (HER2/neu) is overexpressed in 25\% of breast cancer cells, and in other adenocarcinomas of the ovary, lung, prostate and gastrointestinal tract (Baselga et al., 1996). Trastuzumab is a humanized mAb that derived from the murine mAb4D5, which combined with chemotherapy in the randomized phase 3 trial shows a $25 \%$ increase in survival after 29 months than chemotherapy alone. It had also been shown activity in Trastuzumab combination with small- molecule drugs such as vinorelbine, docetaxel and paclitaxel.

Ep-CAM (epithelial cell adhesion molecule) is highly expressed in colorectal, non-small cell lung and prostatic cancer and so on. Edrecolomab, came from murine and transformed into 
human chimeric construct, is a manual antibody for Ep-CAM. The clinical testing showed the chimeric construct increased mononuclear cell-mediated ADCC and prolonged half-life than the murine $\mathrm{mAb}$. In addition, it develops no human anti-mouse antibodies (Hartung et al., 2005).

\subsection{Targets in lymphomas}

The $\mathrm{mAb}$ direct against human $\mathrm{B}$ cell lymphoma-associated antigen have shown enormous power on clearance circulating tumor cells with rare objective clinical responses. The mechanisms underlying responses to these $\mathrm{mAb}$ are complex and have not been completely elucidated now, while the main mechanisms could include ADCC and disturbance transductional signals. Another target, CD52, a glycopeptides exists on $\mathrm{T}$ and $\mathrm{B}$ lymphocytes, has been tested as a target for $\mathrm{mAb}$ in the treatment of numerous lymphomas which decreased the response from allogeneic transplant grafts.

\subsection{Toxicity of mAb}

$\mathrm{mAb}$ are paid more attention as the clinical tests were shown with less toxicity than the normal cytotoxic chemotherapy and radiotherapy. But cytotoxic always emergence through two ways, one is mechanism-dependent and the other is mechanism-independent. Mechanism-independent occur for the mAb proteins produced by the xenogeneic gene. The primary toxicity of $\mathrm{mAbs}$ is mechanism-dependent toxicity that exaggerated pharmacology of blocking or enhancing the activities of the target cells or tissues target molecule. Toxicity is also resulted from binding to the target in normal tissues other than cancer tissues alone. Treatment with cetuximab can cause the skin toxicity (acneiform rash) and the cardiotoxicity observed with trastuzumab due to skin and cardiac muscle respectively expressing the same target antigens.

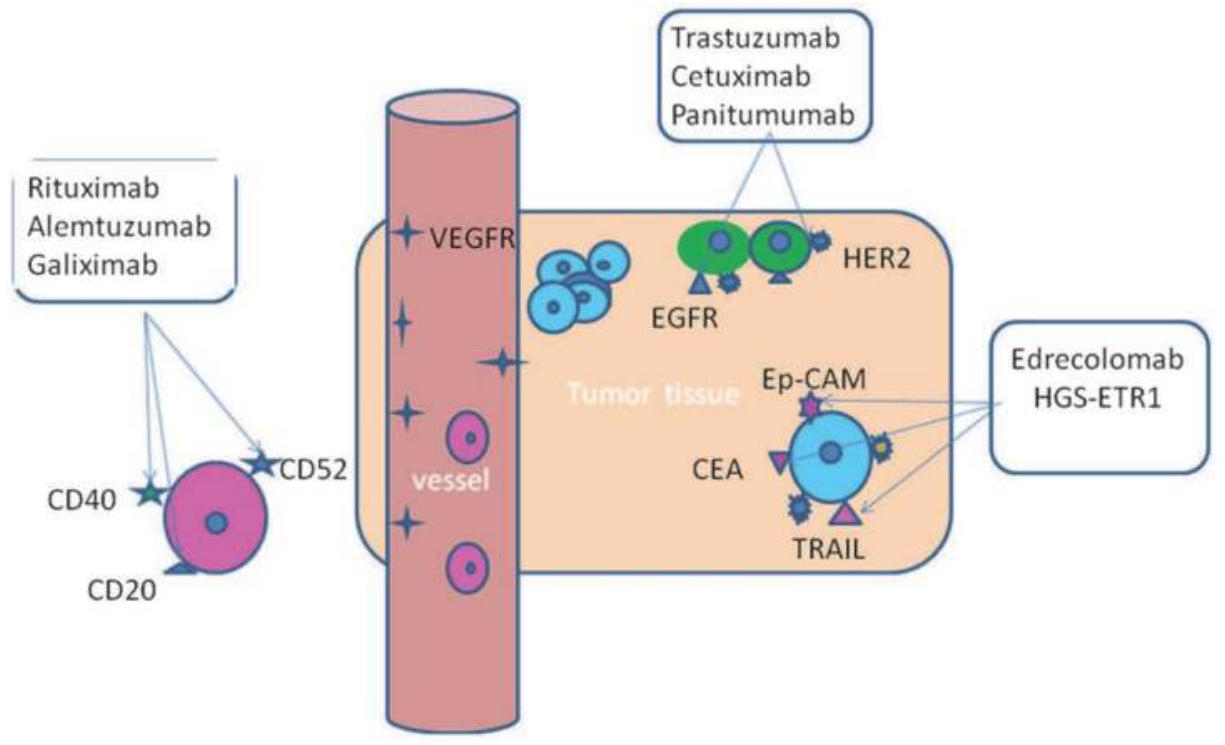

Fig. 4. Targets in solid tumors and lymphomas 


\subsection{Further exploration}

Nowadays mAbs have achieved significantly success compared with the disappointment of failure in decades ago. Despite these accomplishments, the clinical response remains, such as the toxicity on the normal cells. Regardless of these challenges, each new anticancer mAb approved represents more choice and potential benefit to patients. With the development of biotechnology, the efficient and safe mAb for cancer patients may be produced. "We have a long way to go before the story is finished," says Winter (Gura, 2002).

\section{Viral vector for gene delivery}

Cancer is a multigenic disorder involving activation of oncogenes and inactivation of suppressor genes. Many data has suggested that cancer can be arrested or reversed by treatment with gene transfer vectors that carrying therapeutic genes. The vectors used for gene therapy include viral or non-viral vectors. Viruses have been the most common vectors for gene therapy and about $70 \%$ of gene therapy clinical trials use viral vectors. The main viral vectors used in clinic include retroviruses, adenovirus, adeno-associated virus, herpesvirus and poxvirus.

Retrovirus is an enveloped RNA virus. The genome of retrovirus contains two identical single-stranded RNAs about 7-10 kb. There are three open reading frames, gap, pol and env, and two long terminal repeats (LTRs) in retroviral genome (Baum et al., 2006). Replicationdefective retroviral vectors (RDR) lack genes required for self-replication and the capability of cell-to-cell spreading. RDR vectors have used to deliver therapeutic genes into immunodeficiency disease. Replication-competent retrovirus (RCR) vectors can duplicate in dividing cells and result cell lysis. Retrovirus may randomly integrate to host genome and results insertional mutagenesis. Many methods has been explored to improve the safety of RCR vectors, such as using tissue-specific regulatory sequences replace the viral promoter elements; using inducible regulatory sequences to control transcription.

Lentivirus is a kind of slow viruses of the Retroviridae family. In contrast with simple retrovirus, lentivirus has evolved the ability to infect nondividing cells (Cockrell and Kafri, 2007). Recently, the inducible tet-on/off lentivirus expression system has been structured by researchers. Using this system, researchers can control gene expression, so this system is a powerful tool to research transgene expression.

Adenovirus is a linear, double-stranded and non-enveloped DNA virus. The genome of adenovirus is about $36 \mathrm{~kb}$. Over 50 serotypes of human Adenovirus have been identified, among which Ad5 is the most commonly used vector. Unlike the retrovirus, adenovirus genomes do not integrate into the host chromosome, so it is a safe vector for transient transgene expression. Replication-defective adenoviruses have been used to transfer tumorsuppressor genes, anti-angiogenesis genes, immunostimulatory genes, prodrug-activating genes. In 2004, replication-deficient recombinant adenovirus (Ad)-p53 was approved to use for head and neck squamous cell carcinoma (HNSCC) by China's State Food and Drug Administration. In china another cancer gene therapy agentia Ad-endostatin (E10A) has been finished the class I clinical trial for solid cancers and no dose-limiting toxicity was developed (Lin et al., 2007).

Adeno-Associated Virus (AAV) is a small, nonenveloped DNA virus. Its genome is a linear single-stranded DNA of $4.7 \mathrm{~kb}$. AAV produces infection only in the presence of adenovirus or herpesvirus. In the absence of helper virus, AAV can set up latency by integrating into chromosome 19q13.4 (Lai et al., 2002). AAV vectors have successfully delivered targeting 
genes into varieties of dividing and quiescent cells, including in the muscle, liver, lung, brain, eye, retina and heart. The therapeutic genes that AAV vectors contain are no more than 5kb. Researchers invent a new AAV vectors system which uses head-to-tail heterodimers of the two rAAV vectors form via recombination in the ITRs, which can improves the packaging capacity of AAV vectors to $10 \mathrm{~kb}$. This vector has been successfully used for gene expression in the retina, lung and muscle diseases.

Herpes Simplex Virus (HSV) is double-strand DNA virus. HSV-1 is the common vector in gene therapy. The genome of HSV includes long and short unique regions, each flanked by inverted repeats. The neurotropic ability of HSV makes this vector for the design of gene therapies that target cancers of the CNS (Shen and Nemunaitis, 2006). The replicationdefective HSV vector lacks one or several essential immediate-early (IE) genes. Some researchers have used replication-defective HSV vector with suicide genes, such as thymidine kinase (TK) gene or cytosine deaminase (CD), treat CNS malignant tumors. Conditionally replicating HSV vector delete some genes for virus replication, but this vector can duplicate in cancer cells where it gains the enzymes of replication. This vector is an oncolytic HSV vector and has widely used to treat the squamous cancers in head and neck, malignant glioma, colorectal cancer, pancreatic cancer and prostate cancer.

Poxvirus is a kind of complex DNA virus. The genome is linear double-stranded DNA and the size of the different poxvirus species is variable from $130 \mathrm{~kb}$ to $160 \mathrm{~kb}$. The dsDNA molecule contains the open reading frame (ORF) and the inverted terminal repeats (ITRs) in the terminal regions of the genome (Lefkowitz et al., 2006). Poxvirus as a transgene vector with tumor-associated antigens or tumor-specific antigens has been used in cancer therapy, which can improve hose anti-cancer ability.

\section{Nonviral vector for gene delivery}

During the past two decades, gene therapy has gained rapid development as a promising therapeutic modality for the treatment of genetic and acquired disorders (Al-Dosari and Gao, 2009). However, the rate-limiting step is lack of a suitable vector for gene delivery. Although viral vectors are attractive in initial research due to its high efficiency, nonviral gene-delivery carriers have gained increasing attention in recent years because their safety and easy preparation advantages over viral vectors.

Nonviral vectors for gene therapy have been categorized as expression vector and delivery vector. Among the nonviral vectors, the most widely used expression vector is plasmid DNA. Methods of nonviral gene delivery contained direct injection of naked plasmid DNA, physical and chemical approaches (Gao et al., 2007). Physical approaches employing mechanical (particle bombardment or gene gun), electric (electroporation), ultrasonic, or hydrodynamic (hydrodynamic gene transfer) have been explored in recent years. Chemical methods mediate gene uptake by membrane fusion and/or receptor-mediated endocytosis. Chemical vectors such as cationic lipids and cationic polymers form condense complexes with negatively charged DNA through electrostatic interactions (Al-Dosari and Gao, 2009; Ohlfest et al., 2005).

\subsection{Nonviral therapeutics in clinical trials}

Although adenoviral- and retroviral-mediated transfections are currently the most widely used strategies for gene therapy in clinical trials, there are more than 400 clinical trials using 
nonviral vectors so far (www.wiley.co.uk/genmed/clinical). Lipid and polymer-mediated gene delivery has been used to successfully target both genetic diseases as well as cancer. With extensive effort being put into designing nonviral vectors with higher gene transfer efficiency, synthetic gene carriers may become superior to viral analogues in clinical trials in the near future.

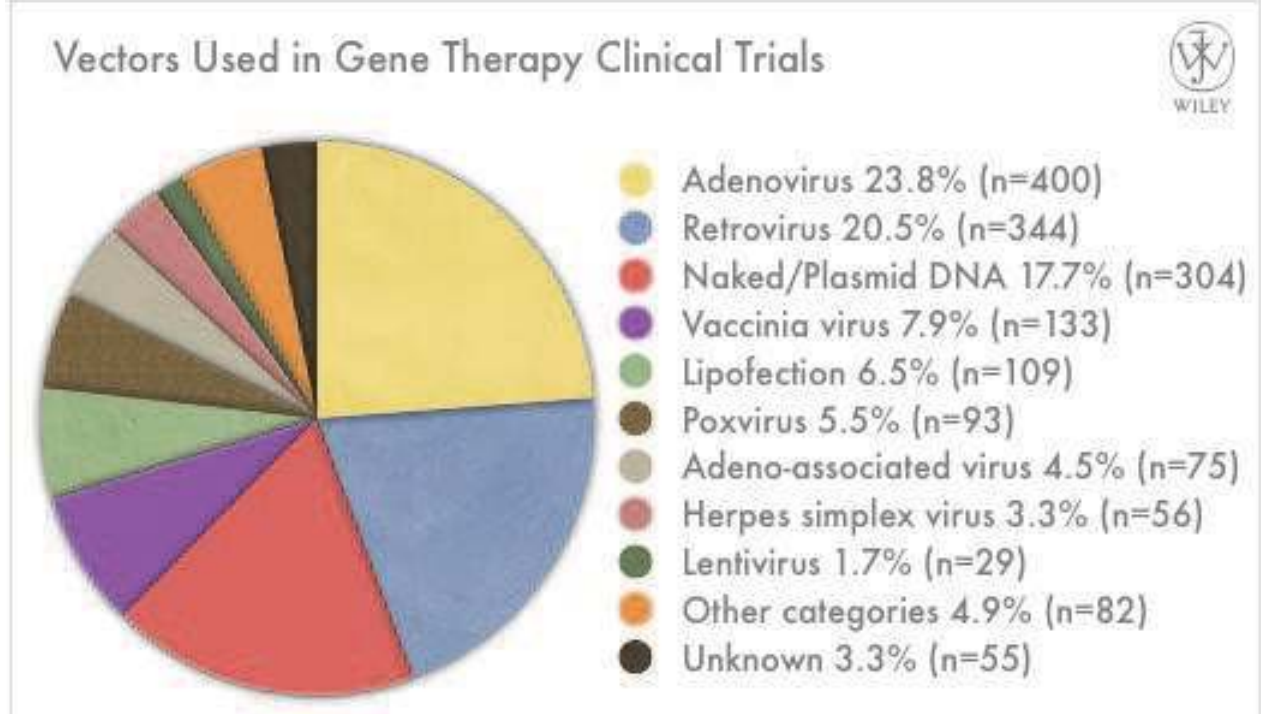

The Journal of Gene Medicine, 2010 John Wiley ond Sons Ltd www.wiley.co.uk/genmed/clinical

Fig. 5. Vectors used in gene therapy

\section{Future direction and challenge}

Single targeted cancer therapy can not be expected to yield optimal outcomes as tumorigenesis is a multistep process and its molecular pathogenesis is not linked to the defect of a single target. Therefore, multi-targeted therapy through the combination of agents targeting distinct molecules might be the goals for targeting therapy in the near future. This could overcome the issues of tumour heterogeneity and maintain the selectivity of treatment at the same time. In addition, monotherapy is further evolving to single inhibitor which can target several molecules simultaneously. It seems promising that with our better understanding of tumor biology, more efficacious combinations for targeted therapy will emerge in the immediate future (Imai and Takaoka, 2006).

Another new aspect of cancer-targeted therapy is employing cancer stem cells as the target. It was reported that mTOR inhibition by rapamycin selectively eliminated leukaemic stem cells without affecting normal haematopoietic stem cells (Zhang et al., 2006). Therefore, targeting abnormal signalling pathway in cancer stem cells might offer an effective approach for targeting therapies. Besides, it is of great importance to identify predictive markers for the response to targeted therapy (Swain, 2011). Beyond its obvious clinical benefits for cancer patients, the identification of predictive markers can also reduce the costs of cancer treatments (Warren et al., 2008). 


\section{References}

Al-Dosari, M.S. and Gao, X. (2009) Nonviral gene delivery: principle, limitations, and recent progress. Aaps J, 11, 671-681.

Baselga, J., Tripathy, D., Mendelsohn, J., Baughman, S., Benz, C.C., Dantis, L., Sklarin, N.T., Seidman, A.D., Hudis, C.A., Moore, J., Rosen, P.P., Twaddell, T., Henderson, I.C. and Norton, L. (1996) Phase II study of weekly intravenous recombinant humanized anti-p185HER2 monoclonal antibody in patients with HER2/neuoverexpressing metastatic breast cancer. J Clin Oncol, 14, 737-744.

Baum, C., Schambach, A., Bohne, J. and Galla, M. (2006) Retrovirus vectors: toward the plentivirus? Mol Ther, 13, 1050-1063.

Bisacchi, D., Benelli, R., Vanzetto, C., Ferrari, N., Tosetti, F. and Albini, A. (2003) Antiangiogenesis and angioprevention: mechanisms, problems and perspectives. Cancer Detect Prev, 27, 229-238.

Bykov, V.J., Issaeva, N., Shilov, A., Hultcrantz, M., Pugacheva, E., Chumakov, P., Bergman, J., Wiman, K.G. and Selivanova, G. (2002) Restoration of the tumor suppressor function to mutant p53 by a low-molecular-weight compound. Nat Med, 8, 282-288.

Chen, L.F., Mu, Y. and Greene, W.C. (2002) Acetylation of RelA at discrete sites regulates distinct nuclear functions of NF-kappaB. Embo J, 21, 6539-6548.

Cockrell, A.S. and Kafri, T. (2007) Gene delivery by lentivirus vectors. Mol Biotechnol, 36, 184-204.

D'Acquisto, F., Sautebin, L., Iuvone, T., Di Rosa, M. and Carnuccio, R. (1998) Prostaglandins prevent inducible nitric oxide synthase protein expression by inhibiting nuclear factor-kappaB activation in J774 macrophages. FEBS Lett, 440, 76-80.

Dell'Eva, R., Pfeffer, U., Indraccolo, S., Albini, A. and Noonan, D. (2002) Inhibition of tumor angiogenesis by angiostatin: from recombinant protein to gene therapy. Endothelium, 9, 3-10.

Deshaies, R.J. and Joazeiro, C.A. (2009) RING domain E3 ubiquitin ligases. Annu Rev Biochem, 78, 399-434.

Dickens, M.P., Fitzgerald, R. and Fischer, P.M. Small-molecule inhibitors of MDM2 as new anticancer therapeutics. Semin Cancer Biol, 20, 10-18.

Folkman, J. (1971) Tumor angiogenesis: therapeutic implications. N Engl J Med, 285, 1182-1186.

Foster, B.A., Coffey, H.A., Morin, M.J. and Rastinejad, F. (1999) Pharmacological rescue of mutant p53 conformation and function. Science, 286, 2507-2510.

Gao, X., Kim, K.S. and Liu, D. (2007) Nonviral gene delivery: what we know and what is next. Aaps J, 9, E92-104.

Granville, C.A., Memmott, R.M., Gills, J.J. and Dennis, P.A. (2006) Handicapping the race to develop inhibitors of the phosphoinositide 3-kinase/Akt/mammalian target of rapamycin pathway. Clin Cancer Res, 12, 679-689.

Guertin, D.A. and Sabatini, D.M. (2007) Defining the role of mTOR in cancer. Cancer Cell, 12, 9-22.

Gura, T. (2002) Therapeutic antibodies: magic bullets hit the target. Nature, 417, 584-586.

Han, E.K., Leverson, J.D., McGonigal, T., Shah, O.J., Woods, K.W., Hunter, T., Giranda, V.L. and Luo, Y. (2007) Akt inhibitor A-443654 induces rapid Akt Ser-473 phosphorylation independent of mTORC1 inhibition. Oncogene, 26, 5655-5661.

Hartung, G., Hofheinz, R.D., Dencausse, Y., Sturm, J., Kopp-Schneider, A., Dietrich, G., Fackler-Schwalbe, I., Bornbusch, D., Gonnermann, M., Wojatschek, C., Lindemann, W., Eschenburg, H., Jost, K., Edler, L., Hochhaus, A. and Queisser, W. (2005) 
Adjuvant therapy with edrecolomab versus observation in stage II colon cancer: a multicenter randomized phase III study. Onkologie, 28, 347-350.

Hennessy, B.T., Smith, D.L., Ram, P.T., Lu, Y. and Mills, G.B. (2005) Exploiting the PI3K/AKT pathway for cancer drug discovery. Nat Rev Drug Discov, 4, 988-1004.

Imai, K. and Takaoka, A. (2006) Comparing antibody and small-molecule therapies for cancer. Nat Rev Cancer, 6, 714-727.

Issaeva, N., Bozko, P., Enge, M., Protopopova, M., Verhoef, L.G., Masucci, M., Pramanik, A. and Selivanova, G. (2004) Small molecule RITA binds to p53, blocks p53-HDM-2 interaction and activates p53 function in tumors. Nat Med, 10, 1321-1328.

Jiang, B.H. and Liu, L.Z. (2008) PI3K/PTEN signaling in tumorigenesis and angiogenesis. Biochim Biophys Acta, 1784, 150-158.

Jin, X., Gossett, D.R., Wang, S., Yang, D., Cao, Y., Chen, J., Guo, R., Reynolds, R.K. and Lin, J. (2004) Inhibition of AKT survival pathway by a small molecule inhibitor in human endometrial cancer cells. Br J Cancer, 91, 1808-1812.

Karin, M., Yamamoto, Y. and Wang, Q.M. (2004) The IKK NF-kappa B system: a treasure trove for drug development. Nat Rev Drug Discov, 3, 17-26.

Kohler, G. and Milstein, C. (1975) Continuous cultures of fused cells secreting antibody of predefined specificity. Nature, 256, 495-497.

Kruse, J.P. and Gu, W. (2009) Modes of p53 regulation. Cell, 137, 609-622.

Ku, G.Y. andIson, D.H. (2010) Esophagogastric cancer: targeted agents. Cancer Treat Rev, 36, 235248.

Lai, C.M., Lai, Y.K. and Rakoczy, P.E. (2002) Adenovirus and adeno-associated virus vectors. DNA Cell Biol, 21, 895-913.

Lefkowitz, E.J., Wang, C. and Upton, C. (2006) Poxviruses: past, present and future. Virus Res, 117, 105-118.

Lin, X., Huang, H., Li, S., Li, H., Li, Y., Cao, Y., Zhang, D., Xia, Y., Guo, Y., Huang, W. and Jiang, W. (2007) A phase I clinical trial of an adenovirus-mediated endostatin gene (E10A) in patients with solid tumors. Cancer Biol Ther, 6, 648-653.

Lo, H.W. Nuclear mode of the EGFR signaling network: biology, prognostic value, and therapeutic implications. Discov Med, 10, 44-51.

Martelli, A.M., Tazzari, P.L., Tabellini, G., Bortul, R., Billi, A.M., Manzoli, L., Ruggeri, A., Conte, R. and Cocco, L. (2003) A new selective AKT pharmacological inhibitor reduces resistance to chemotherapeutic drugs, TRAIL, all-trans-retinoic acid, and ionizing radiation of human leukemia cells. Leukemia, 17, 1794-1805.

Mendez, M.J., Green, L.L., Corvalan, J.R., Jia, X.C., Maynard-Currie, C.E., Yang, X.D., Gallo, M.L., Louie, D.M., Lee, D.V., Erickson, K.L., Luna, J., Roy, C.M., Abderrahim, H., Kirschenbaum, F., Noguchi, M., Smith, D.H., Fukushima, A., Hales, J.F., Klapholz, S., Finer, M.H., Davis, C.G., Zsebo, K.M. and Jakobovits, A. (1997) Functional transplant of megabase human immunoglobulin loci recapitulates human antibody response in mice. Nat Genet, 15, 146-156.

Moy, B., Kirkpatrick, P., Kar, S. and Goss, P. (2007) Lapatinib. Nat Rev Drug Discov, 6, 431-432.

O'Reilly, M.S., Boehm, T., Shing, Y., Fukai, N., Vasios, G., Lane, W.S., Flynn, E., Birkhead, J.R., Olsen, B.R. and Folkman, J. (1997) Endostatin: an endogenous inhibitor of angiogenesis and tumor growth. Cell, 88, 277-285.

O'Reilly, M.S., Holmgren, L., Shing, Y., Chen, C., Rosenthal, R.A., Moses, M., Lane, W.S., Cao, Y., Sage, E.H. and Folkman, J. (1994) Angiostatin: a novel angiogenesis inhibitor that mediates the suppression of metastases by a Lewis lung carcinoma. Cell, 79, 315-328. 
Ohlfest, J.R., Freese, A.B. and Largaespada, D.A. (2005) Nonviral vectors for cancer gene therapy: prospects for integrating vectors and combination therapies. Curr Gene Ther, 5, 629-641.

Park, D. and Dilda, P.J. Mitochondria as targets in angiogenesis inhibition. Mol Aspects Med, 31, 113-131.

Reichert, J.M., Rosensweig, C.J., Faden, L.B. and Dewitz, M.C. (2005) Monoclonal antibody successes in the clinic. Nat Biotechnol, 23, 1073-1078.

Sebolt-Leopold, J.S., Dudley, D.T., Herrera, R., Van Becelaere, K., Wiland, A., Gowan, R.C., Tecle, H., Barrett, S.D., Bridges, A., Przybranowski, S., Leopold, W.R. and Saltiel, A.R. (1999) Blockade of the MAP kinase pathway suppresses growth of colon tumors in vivo. Nat Med, 5, 810-816.

Sebolt-Leopold, J.S. and Herrera, R. (2004) Targeting the mitogen-activated protein kinase cascade to treat cancer. Nat Rev Cancer, 4, 937-947.

Secchiero, P., di Iasio, M.G., Gonelli, A. and Zauli, G. (2008) The MDM2 inhibitor Nutlins as an innovative therapeutic tool for the treatment of haematological malignancies. Curr Pharm Des, 14, 2100-2110.

Shen, Y. and Nemunaitis, J. (2006) Herpes simplex virus 1 (HSV-1) for cancer treatment. Cancer Gene Ther, 13, 975-992.

Swain, S.M. (2011). Chemotherapy: updates and new perspectives. Oncologist, 16 Suppl 1, 30-39.

Tang, H.J., Jin, X., Wang, S., Yang, D., Cao, Y., Chen, J., Gossett, D.R. and Lin, J. (2006) A small molecule compound inhibits AKT pathway in ovarian cancer cell lines. Gynecol Oncol, 100, 308-317.

Thomas, J.P., Arzoomanian, R.Z., Alberti, D., Marnocha, R., Lee, F., Friedl, A., Tutsch, K., Dresen, A., Geiger, P., Pluda, J., Fogler, W., Schiller, J.H. and Wilding, G. (2003) Phase I pharmacokinetic and pharmacodynamic study of recombinant human endostatin in patients with advanced solid tumors. J Clin Oncol, 21, 223-231.

Tomita, N., Ogihara, T. and Morishita, R. (2003) Transcription factors as molecular targets: molecular mechanisms of decoy ODN and their design. Curr Drug Targets, 4, 603-608.

Vousden, K.H. and Lu, X. (2002) Live or let die: the cell's response to p53. Nat Rev Cancer, 2, 594-604.

Vousden, K.H. and Prives, C. (2009) Blinded by the Light: The Growing Complexity of p53. Cell, 137, 413-431.

Warren, J.L., Yabroff, K.R., Meekins, A., Topor, M., Lamont, E.B. and Brown, M.L. (2008) Evaluation of trends in the cost of initial cancer treatment. J Natl Cancer Inst, 100, 888-897.

Willett, C.G., Boucher, Y., di Tomaso, E., Duda, D.G., Munn, L.L., Tong, R.T., Chung, D.C., Sahani, D.V., Kalva, S.P., Kozin, S.V., Mino, M., Cohen, K.S., Scadden, D.T., Hartford, A.C., Fischman, A.J., Clark, J.W., Ryan, D.P., Zhu, A.X., Blaszkowsky, L.S., Chen, H.X., Shellito, P.C., Lauwers, G.Y. and Jain, R.K. (2004) Direct evidence that the VEGF-specific antibody bevacizumab has antivascular effects in human rectal cancer. Nat Med, 10, 145-147.

Zhang, J., Grindley, J.C., Yin, T., Jayasinghe, S., He, X.C., Ross, J.T., Haug, J.S., Rupp, D., Porter-Westpfahl, K.S., Wiedemann, L.M., Wu, H. and Li, L. (2006) PTEN maintains haematopoietic stem cells and acts in lineage choice and leukaemia prevention. Nature, 441, 518-522. 


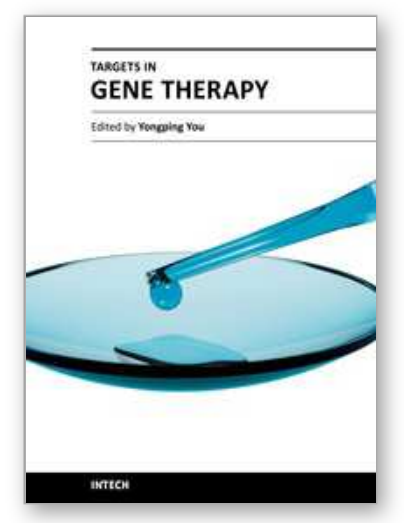

\author{
Targets in Gene Therapy \\ Edited by Prof. Yongping You
}

ISBN 978-953-307-540-2

Hard cover, 436 pages

Publisher InTech

Published online 23, August, 2011

Published in print edition August, 2011

This book aims at providing an up-to-date report to cover key aspects of existing problems in the emerging field of targets in gene therapy. With the contributions in various disciplines of gene therapy, the book brings together major approaches: Target Strategy in Gene Therapy, Gene Therapy of Cancer and Gene Therapy of Other Diseases. This source enables clinicians and researchers to select and effectively utilize new translational approaches in gene therapy and analyze the developments in target strategy in gene therapy.

\title{
How to reference
}

In order to correctly reference this scholarly work, feel free to copy and paste the following:

Yufang Zuo, Xiaofang Ying, Hui Wang, Wen Ye, Xiangqi Meng, Hongyan Yu, Yi Zhou, Wuguo Deng and Wenlin Huang (2011). Current Strategies for Cancer Gene Therapy, Targets in Gene Therapy, Prof. Yongping You (Ed.), ISBN: 978-953-307-540-2, InTech, Available from: http://www.intechopen.com/books/targets-ingene-therapy/current-strategies-for-cancer-gene-therapy

\section{INTECH}

open science | open minds

\section{InTech Europe}

University Campus STeP Ri

Slavka Krautzeka 83/A

51000 Rijeka, Croatia

Phone: +385 (51) 770447

Fax: +385 (51) 686166

www.intechopen.com

\section{InTech China}

Unit 405, Office Block, Hotel Equatorial Shanghai

No.65, Yan An Road (West), Shanghai, 200040, China 中国上海市延安西路 65 号上海国际贵都大饭店办公楼 405 单元

Phone: +86-21-62489820

Fax: $+86-21-62489821$ 
(C) 2011 The Author(s). Licensee IntechOpen. This chapter is distributed under the terms of the Creative Commons Attribution-NonCommercialShareAlike-3.0 License, which permits use, distribution and reproduction for non-commercial purposes, provided the original is properly cited and derivative works building on this content are distributed under the same license. 